MATEC Web of Conferences 33, 03011 (2015)

DOI: $10.1051 /$ matec conf/ 20153303011

(c) Owned by the authors, published by EDP Sciences, 2015

\title{
Phase Transformations and Fatigue of $\mathrm{NiTi}$
}

\author{
Eduardo Alarcon ${ }^{1,2, a}$, Ludek Heller ${ }^{2}$, Shabnam Arbab Chirani ${ }^{1}$, Petr Sittner ${ }^{2}$, Luc Saint-Sulpice ${ }^{1}$ and Sylcain Calloch ${ }^{3}$ \\ ${ }^{1}$ LBMS, ENIB, Technopôle Brest-Iroise, CS73862, 29238 Brest, France \\ ${ }^{2}$ Institute of Physics, Academy of Sciences of the Czech Republic, 18200 Prague, Czech Republic \\ ${ }^{3}$ LBMS, ENSTA Bretagne, 29200 Brest, France
}

\begin{abstract}
Tensile fatigue of superelastic medical graded NiTi wires was analysed in stress control regime with special attention paid to the deformation/transformation processes involved. Concave shaped samples were machined from NiTi wires allowing us to confine deformation processes into the centre of the sample. The localization of phase transformations within the centre was confirmed using in-situ infrared imaging. Characteristic stress-displacement responses for amplitudes inducing either R-phase only or both R-phase and martensite were identified for these samples. A limited number of pull-pull fatigue tests in force-control regime were performed. The obtained S-N curve and associated stress-displacement responses allowed for identification of three fatigue regimes differing in the fatigue life-time by orders of magnitude. Particularly, fatigue life-time deteriorating effect of R-phase transformation was identified.
\end{abstract}

\section{Introduction}

Mechanical fatigue may be thought as a change in material properties due to mere repeated application of stresses or strains which can finally lead to cracking or failure. Origins of fatigue cracks of polycrystalline solids are often associated with irreversible shear displacement along slip bands [1]. However there are many material factors affecting the fatigue properties such as stress and strain state, grain size, precipitates, impurities, inclusions, texture, surface finish as well as phase transitions including martensitic transformation, which gives rise to functional properties of shape memory alloys. From the early days of Nitinol research, it has been known that thermoelastic martensitic transformation is accompanied by dislocation slip and accumulation of residual martensite [2]. These irreversible processes are often blamed for the functional fatigue as well as the drop in fatigue performance systematically reported whenever the loading enters the martensitic transformation (MT) regime [3]. This low cycle fatigue (LCF) is contrasted with high cycle fatigue (HCF) observed at lower strain/stress amplitudes within the Austenite elasticity (ratio between maximal stress applied and martensite transformation stress between 0.3 and 0.7) [4]. Moreover, heat treated cold worked wires used in applications exhibit R-phase transformation preceding the MT [5]. This transformation has to be also considered in fatigue analysis of NiTi wires as a distinct deformation process although it shows much lower transformation strains and negligible hysteresis compared to MT. Surprisingly, the role of R-phase transformation in the fatigue of Nitinol has not been extensively studied.
As in other engineering materials, two different approaches can be adopted to characterize the mechanical fatigue of Nitinol: defect-tolerant (crack propagation analysis) and total-life (characterization of total fatigue life-time to failure in terms on cyclic stress or strain range) [1]. Melton and Mercier [4] were the first to investigate the fatigue behaviour of Nitinol under the two aforementioned approaches. Since then, several fatigue studies have been carried out using different testing procedures. For medical devices, the Bending-rotation fatigue (BRF) testing is widely used [6][7][8]. Fatigue of laser-cut struts, the building units of medical stents, are often tested in cyclic tension-compression [9][10]. Other studies present results of the behaviour of Nitinol tubes under cyclic tension-tension (pull-pull) [11]. Classical pull-pull fatigue tests have been performed on Nitinol wires and sheets as well. Dog bone samples, cut from wire electro discharge machining, were tested in [12] in order to investigate the pull-pull fatigue behaviour of Nitinol sheets. In the case of pull-pull fatigue of Nitinol wires, most of the results in literature are from straight non-machined samples [13][14]. However, from our experience, these samples are not suitable for HCF tests since they tend to fail within the jaws of the fatigue device, which puts the obtained number of cycles in doubts.

In this paper, we present first results in the context of complex fatigue investigations being carried out on concave shaped superelastic Nitinol wires. First, we introduce investigated NiTi material and particularly the concave geometry of NiTi samples tested in fatigue. Second, we describe typical tensile responses of concave shaped samples including data from in-situ infrared imaging showing the localization of transformation

\footnotetext{
${ }^{\mathrm{a}}$ Corresponding author: eduardo.alarcon@ensta-bretagne.org
} 
processes. Finally, we present fatigue data gathered so far from "pull-pull" tests. Namely, the S-N curve interpreted using tensile fatigue responses and their evolutions during fatigue cycling.

\section{Material and samples geometry}

In order to confine the stress-induced phase transformation and other deformation processes proceeding in NiTi, concave samples were produced as shown in Figure 1. The grinding was applied to machine a concave $5 \mathrm{~mm}$ long profile with radius of $10 \mathrm{~mm}$ within the central section of $40 \mathrm{~mm}$ long NiTi wires of diameter $1.78 \mathrm{~mm}$. The diameter at mid-cross-section was decreased by grinding down to $1.14 \mathrm{~mm}$.

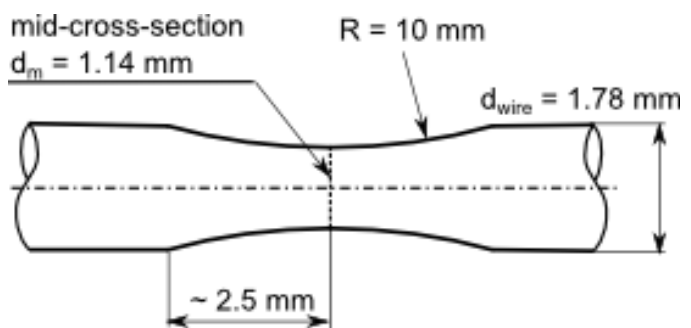

Figure 1 Geometry of concave shaped samples made from $1.78 \mathrm{~mm}$ as drawn NiTi wires by grinding followed by electropolishing.

The concave geometry acts as stress raiser, ideal for pull-pull fatigue tests of NiTi wires since there is no shear band localization of strain. Besides, the volume which transforms during the forward and reverse MT is strongly confined in the centre of the sample. Local changes in sample's temperature due to latent heat absorption/release might be effectively suppressed by heat conduction into surrounding non-transforming material. Therefore, the wire stress-strain response might be less rate dependent. Concave geometry is also more suitable for microscopic observations because all the deformation processes are localized into a well-defined spot. On the other hand, material strains and stresses vary along the length of the sample.

Motivated by fatigue endurance of NiTi wires used in medical application, we selected a medical graded superelastic NiTi wire of diameter $1.78 \mathrm{~mm}$ provided in as drawn condition by Fort Wayne Metals Ltd. The provider specified the composition of the raw material as 50.92 at. $\% \mathrm{Ni}$ and cold-work of about $40 \%$. The as drawn wires were machined into concave shaped samples as explained above. Afterwards, electropolishing was performed in order to remove surface defects and oxide. Finally, samples were heat treated at $500^{\circ} \mathrm{C}$ for $30 \mathrm{~min}$ in constrained straight shape and water quenched.

Phase transformation temperatures of the heat treated sample were measured by Differential Scanning Calorimetry (DSC). From the DSC curve shown in Figure 2, phase transformation temperatures listed in Table 1 were identified. Note that the R-phase peak is located near the room temperature denoted in Figure 2 by the vertical line.

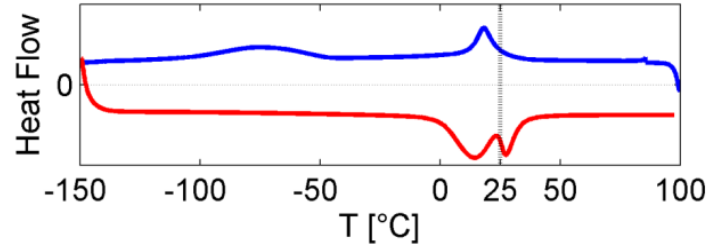

Figure 2 DSC curve of NiTi concave shape samples for fatigue testing. The samples were prepared from raw NiTi material with composition of 50.92 at. \% $\mathrm{Ni}$ that was cold worked down to $1.78 \mathrm{~mm}$ wires with final cold work of about $40 \%$. Then the concave shape was machined and, afterwards, the samples were heat treated at $500^{\circ} \mathrm{C}$ for $30 \mathrm{~min}$. and water quenched.

Table 1 Phase transformation temperatures identified from the DSC curve.

\begin{tabular}{|c|c|}
\hline & ${ }^{\circ} \mathbf{C}$ \\
\hline As & 21.45 \\
\hline Af & 34.52 \\
\hline Rs & 26.48 \\
\hline Rf & 12.15 \\
\hline Ms & -46.16 \\
\hline Mf & -105.9 \\
\hline
\end{tabular}

\section{Experimental conditions}

Static tensile and pull-pull fatigue tests were carried out using an Instron 8872 servohydraulic fatigue testing device in a thermal chamber at $40^{\circ} \mathrm{C}$. Testing temperature is thus well above the $A_{f}$ temperature (see Table 1 for identified transformation temperatures). The temperature of the environment was monitored by two thermocouples placed near the sample and at the inner chamber casing. In order to estimate the strain, a $10 \mathrm{~mm}$ gauge-length clip-on extensometer was placed at the centre of the concave section of samples. Extensometer controlled tensile tests at a rate of $2.4 \times 10^{-4} \mathrm{~mm} . \mathrm{s}^{-1}$ were performed to characterize the tensile response of NiTi samples. Fatigue tests were performed in a force-controlled regime at $25 \mathrm{~Hz}$ and stress ratio $\left(R=\sigma_{\max } / \sigma_{\min }\right)$ equal to 0.1 . All tensile responses are presented in terms of the engineering stress at the mid-cross-section (applied load divided by the initial mid-cross-section area) plotted against the displacement recorded between the extensometer arms surrounding the concave part.

We also include results of additional experiments characterizing deformation processes in concave shaped samples using stress-displacement-temperature evolutions performed in force controlled tension on Bose Electroforce 3300 with in-situ infrared imaging using fast Flir SC7000 (max. $200 \mathrm{~Hz}$ ). Note that the clip-on extensometer was not used here and the grip displacement were considered instead. 


\section{Phase transformations in concave shaped NiTi samples}

As introduced above, degradation of fatigue performance of superelastic nitinol correlates with the appearance of MT. Hence, before any meaningful tensile fatigue testing on concaved shaped samples we have to understand how the transformations proceed in such shaped samples upon tensile loading. Therefore, we performed in-situ infrared imaging to trace the onset of transformation processes in concave shaped NiTi samples subjected to force controlled tensile loadings. Note that this study was performed on samples that received different heat treatment from the one used for the fatigue analysis.

We studied two concave shaped samples that received different thermal treatments and analysed the responses of a solution heat treated sample undergoing directed austenite-martensite transformation path and annealed sample undergoing sequential austentite-R-phasemartensite transformation path. The solutionized sample was prepared by solution heat treatment at $800^{\circ} \mathrm{C}$ for $2 \mathrm{~h}$ followed by water quenching. The annealed sample was prepared by annealing at $450^{\circ} \mathrm{C}$ for $30 \mathrm{~min}$. The transformation paths were verified using DSC measurements the results of which are not shown here for the sake of brevity.
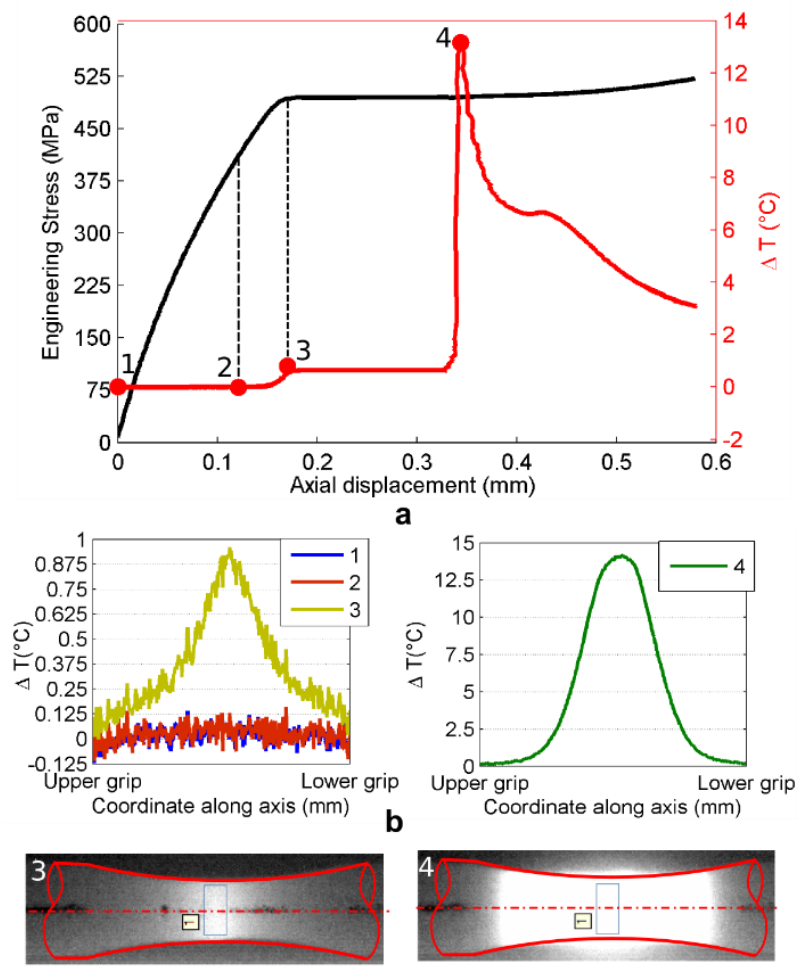

$26^{\circ} \mathrm{C}$ c $24.84^{\circ} \mathrm{C}$

Figure 3 a Stress-displacement-temperature evolutions obtained during force controlled tensile loading $(4 \mathrm{~N} / \mathrm{s})$ of the solutionized sample. b Temperature profiles related to loading stages numbered in a. c Infrared images related to denoted loading stages.

Figures 3 and 4 summarize stress-displacementtemperature evolutions as recorded during force controlled tensile loading on the solutionized (loading rate $4 \mathrm{~N} / \mathrm{s}$ ) and annealed samples (loading rate $4.9 \mathrm{~N} / \mathrm{s}$ ), respectively. We suppose that the increase in temperature measured on the annealed sample between loading stages 2 and 3 (see Figure $4 \mathrm{a}$ and related temperature profiles 2 and 3 in $4 \mathrm{~b}$ ) is associated with the austenite-R-phase transformation temperature as the solutionized sampled doesn't present such a temperature increase at the corresponding loading range denoted 1 and 2 in Figure $3 a$ (see also related temperature profiles in Figure $3 \mathrm{~b}$ ). The following transformations from R-phase to martensite as well as from austenite to martensite are marked with pronounced peaks in temperature-displacement evolutions as seen in Figure $4 \mathrm{a}$ and $3 \mathrm{a}$, respectively. Moreover, the related temperature increases is well localized around the mid-cross-sections (see temperature profiles 3, 4 in Figure $3 b$ and 4, 5 in Figure $4 b$ ). The increase in temperature and localization of temperature peaks suggest that the martensitic transformation clearly proceeds from the early stage of the plateau appearance in stress-displacement evolutions (loading stages denoted 3 in Figure $3 \mathrm{a}$ for the solutionized sample and 4 in Figure 4 a for annealed sample).
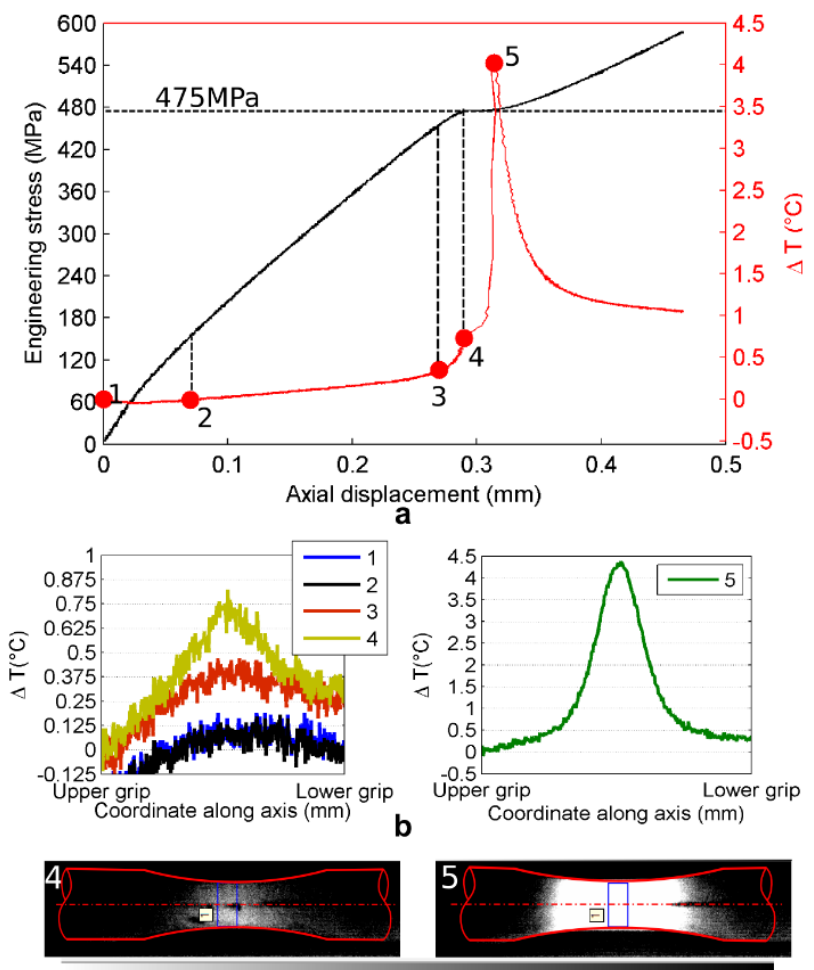

$25^{\circ} \mathrm{C}$

C

$24.5^{\circ} \mathrm{C}$

Figure 4 a Stress-displacement-temperature evolutions as obtained during force controlled tensile loading $(4 \mathrm{~N} / \mathrm{s})$ of the annealed sample. b Temperature profiles related to loading stages numbered in a. c Infrared images related to denoted loading stages.

This in-situ infrared imaging study confirmed that the concave shaped samples, indeed, confine the transformation processes to the concave section of the sample. In addition, at the onset of the plateau in stressdisplacement evolution the MT is effectively triggered right at the mid-cross-section of the concave section. 


\section{Static tensile characterization}

To identify the onset of MT and R-phase transformations in samples for fatigue testing we measured static loadingunloading tensile responses of virgin samples. The tests were done at temperatures $40^{\circ} \mathrm{C}$ at which the fatigue testing was performed in clip-on extensometer controlled loading regime at a rate of $2.4 \times 10^{-4} \mathrm{~mm} . \mathrm{s}^{-1}$. Figure 5 shows responses measured at amplitudes below the onset of MT (1), at the onset of MT (2) and above the onset of MT (3). The onset of MT was identified at $\sigma_{M}=$ $607 \mathrm{MPa}$. Although the response (1) looks like a linear elastic response of austenite, it deviates from linearity at $\sim 150 \mathrm{MPa}$ as clearly seen in Figure 6 . We suppose that this is due to the onset of austenite-R-phase transformation as Rs temperature is near the room temperature (see Table 1) and, moreover, the corresponding response at $80^{\circ} \mathrm{C}$ is perfectly linear (see Figure 7) as expected from the Clausius-Clapeyron temperature dependence of R-phase transformation stresses.

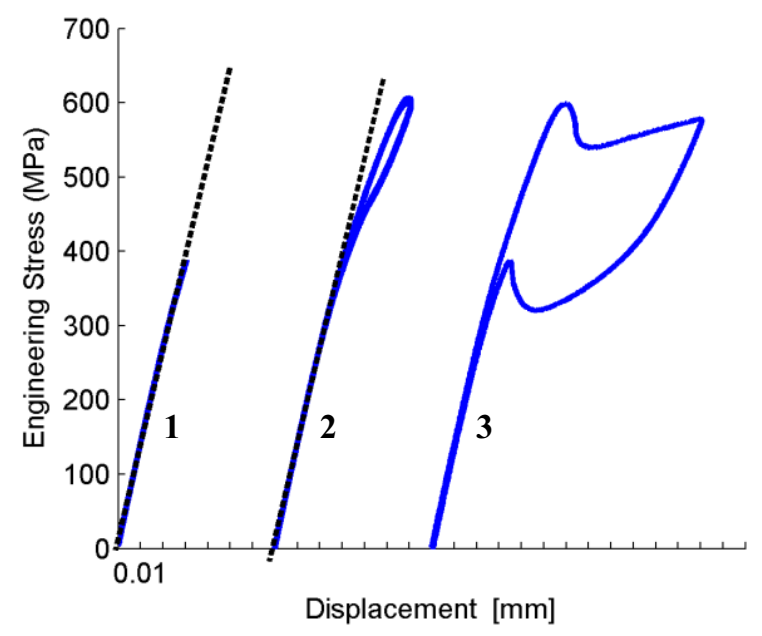

Figure 5 Tensile responses of concave shaped samples at $40^{\circ} \mathrm{C}$ at three particular displacement amplitudes -1 below onset of MT, 2 at the onset of MT, 3 beyond the onset of MT.

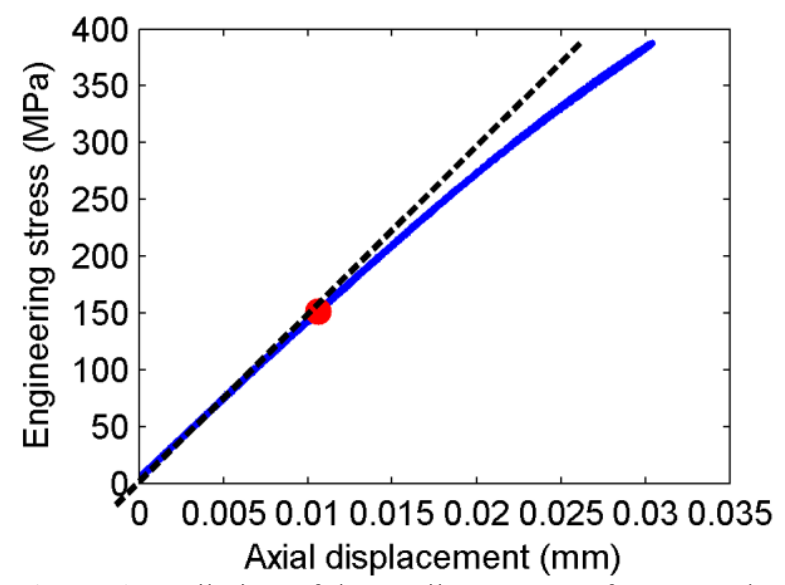

Figure 6 Detail view of the tensile response of concave shaped samples at $40^{\circ} \mathrm{C}$, at an amplitude below the onset of MT. The tensile response feature non-linear non-hysteretic shape suggesting that the R-phase is involved in deformation mechanism. The presumable R-phase onset at $\sim 150 \mathrm{MPa}$ is denoted by red bullet.

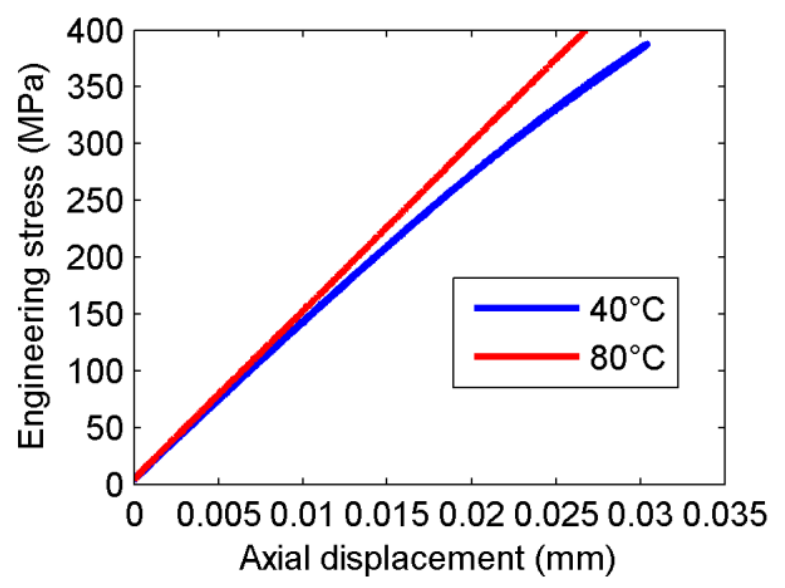

Figure 7 Comparison of tensile responses at a fixed stress amplitude below the onset of MT measured at $40^{\circ} \mathrm{C}$ showing nonlinear shape probably due to R-phase transformation and at $80^{\circ} \mathrm{C}$ showing linear response suggesting that only Austenite elasticity takes place.

\section{$6 \quad$ Fatigue testing}

Fatigue tests were performed in a force-controlled regime at frequency of $25 \mathrm{~Hz}$ and stress ratio $(R=$ $\left.\sigma_{\max } / \sigma_{\min }\right)$ equal to 0.1 . A fatigue runout test was defined at $1.5 \times 10^{6}$ cycles. All failures occurred in midcross-section of the concave zone. Only one test was performed for each applied amplitude, so no statistical measures could be evaluated. Nevertheless, the measured $\mathrm{S}-\mathrm{N}$ curve shown in Figure $8 \mathrm{~b}$ shows rather continuous decrease in number of cycles before fracture with increasing applied stress amplitude. The fatigue limit of the material $\left(\Sigma_{\infty}\right)$ was identified at $397 \mathrm{MPa}$ using the staircase method [15]. Beyond this limit the fatigue lifetime drops to $10^{5}$ cycles and rather continuously decreases down to few $10^{4}$ cycles. The fatigue life-time drops down again to few thousands of cycles at stress amplitude of $650 \mathrm{MPa}$ being above the onset of MT $\left(\sigma_{M}=607 \mathrm{MPa}\right)$. To associate deformation processes with different stages of fatigue performance, stressdisplacement responses recorded in $100^{\text {th }}$ cycle of three particular fatigue tests are plotted in Figure 8a. Runout tests show nonlinear reversible responses suggesting that the austenite-R-phase transformation takes place. Similarly, tests at stress amplitudes ranging from 450 $\mathrm{MPa}$ to $500 \mathrm{MPa}$ with reduced fatigue life-time by two orders of magnitude feature nonlinear reversible responses, however, in this R-phase fatigue regime, samples underwent larger displacements. Finally, the test at stress amplitude of $650 \mathrm{MPa}$ with reduced fatigue lifetime by 3 orders of magnitude, shows nonlinear hysteretic response suggesting that MT operates. Therefore we may classify the fatigue performance of the wire into 3 regimes:

- High cycle fatigue R-phase regime at moderate displacements. 
- Low cycle fatigue R-phase regime at larger displacements featuring amplitude dependent life-time ranging from $10^{5}$ to $10^{4}$ cycles

- Low cycle fatigue MT regime with life-times in the range of $10^{3}$ cycles

This classification is based on rather low number of fatigue tests, therefore, further tests are needed to confirm this conclusion.

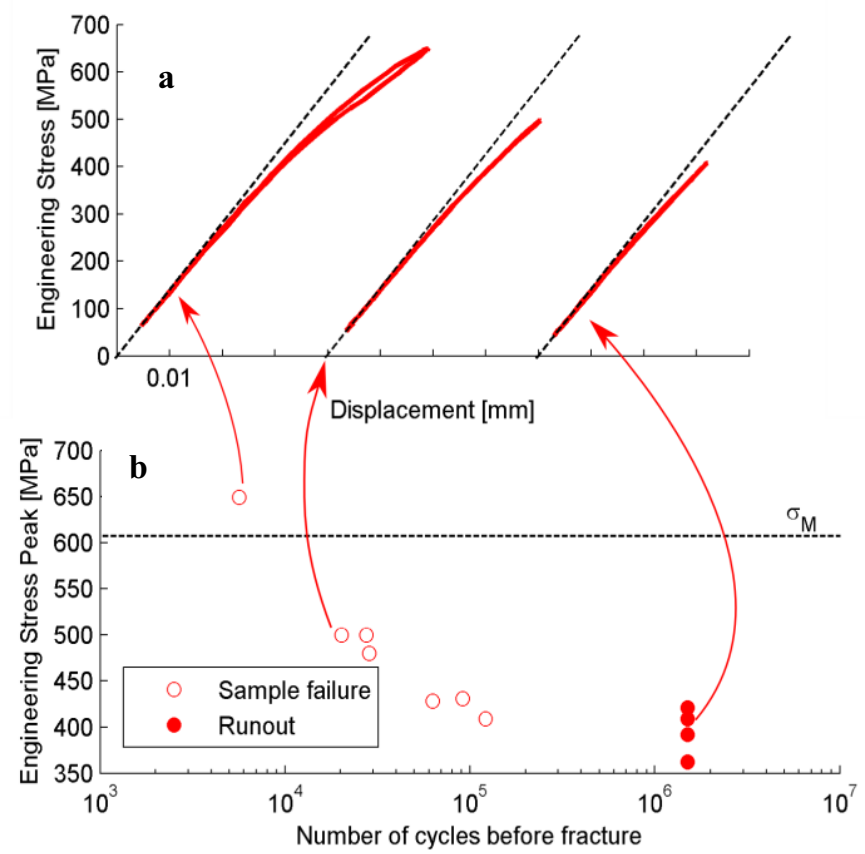

Figure 8 a- Three typical tensile responses within the stress amplitude range covered during fatigue, the responses were measured at the $100^{\text {th }}$ b- S-N curve resulting from pull-pull fatigue tests performed on concave shaped samples at $40^{\circ} \mathrm{C}$.

In accordance with this classification, we propose a "Fatigue failure advanced warning" in terms of pronounced hysteresis appearing on stress-displacement curve before failure. In case of R-phase fatigue regime, hysteresis appears and continuously growths within approximately 100 cycles before failure occurs. In case of MT fatigue regime showing inherent hysteresis from the first cycle, hysteresis starts increasing within approximately 100 cycles before failure occurs as illustrated in Figure 9. Note that the hysteresis may change continuously even before the final 100 cycles, however, the change become noticeable right before the failure.

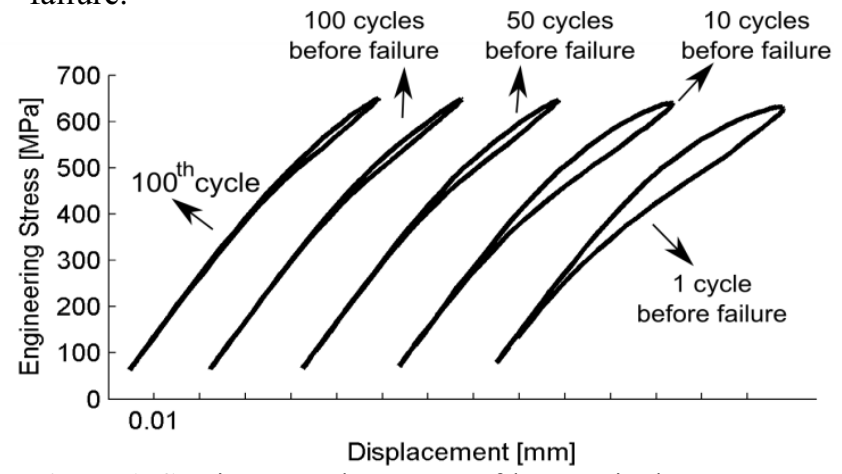

Figure 9 Continuous enlargement of hysteresis that appears as advanced failure warning within 100 cycles before failure during a low cycle MT fatigue regime test at stress amplitude of $650 \mathrm{MPa}$ and temperature of $40^{\circ} \mathrm{C}$.

To investigate the R-phase transformation in fatigue of NiTi wires, we compared fatigue performance at a fixed stress amplitude of $450 \mathrm{MPa}$ and different temperatures: $40^{\circ} \mathrm{C}, 80^{\circ} \mathrm{C}, 150^{\circ} \mathrm{C}$. Although the stress amplitudes were equal, tests at $80^{\circ} \mathrm{C}$ and $150^{\circ} \mathrm{C}$ ran out at maximum number of cycles, whereas test at $40^{\circ} \mathrm{C}$ finished by a failure after just $\sim 30,000$ cycles. When comparing the responses at respective temperatures (see Figure 10) we notice that the response at the temperature of $40^{\circ} \mathrm{C}$ is nonlinear suggesting that austenite- $\mathrm{R}$-phase is involved as operating deformation mechanism i.e. low cycle fatigue R-phase regime is in place. At two higher temperatures of $80^{\circ} \mathrm{C}$ and $150^{\circ} \mathrm{C}$, the sample responses feature rather linear slopes suggesting that austenite elasticity takes place or the moderate displacement high cycle fatigue R-phase regime is entered at $80^{\circ} \mathrm{C}$ as its slope is lower than at $150^{\circ} \mathrm{C}$ i.e. high cycle fatigue Austenite regime $\left(150^{\circ} \mathrm{C}\right)$ and R-phase regime with moderate amplitude $\left(80^{\circ} \mathrm{C}\right)$ take place.

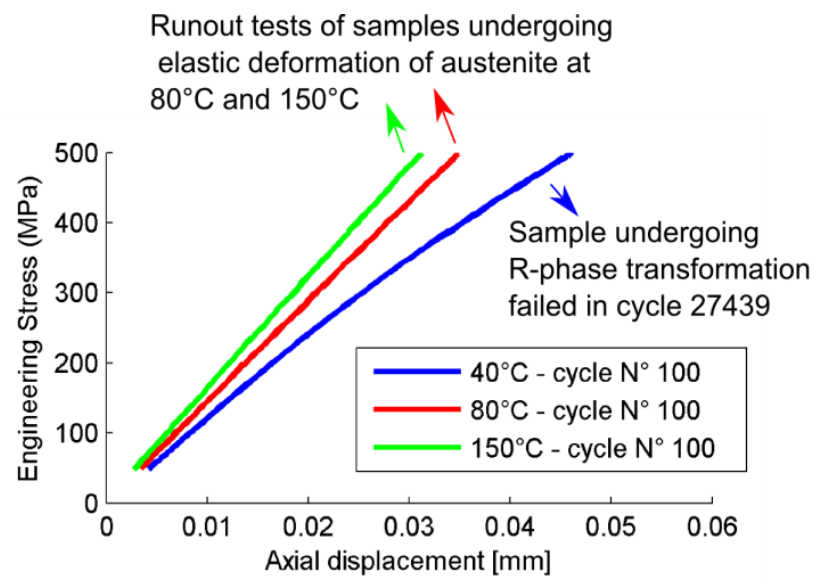

Figure 10 Fatigue tensile responses in cycle 100 of three fatigue tests performed at a fixed stress amplitude of $450 \mathrm{MPa}$ and three different temperatures.

\section{Conclusions}

We have investigated tensile pull-pull fatigue of superelastic NiTi wires in view of the involved deformation/transformation processes. Fatigue-life approach and concave shaped samples were purposely machined from NiTi wires in order to confine the transformation processes into a small and well localized material volume.

In-situ infrared imaging during tensile loading of concave shaped samples confirmed the localization of deformation/transformation processes into the centre of the sample and linked the onset of the plateau in stressdisplacement evolution with the onset of martensitic transformation.

A limited number of fatigue tests were performed on concave shaped samples showing rather regular decrease of material life-time with increasing stress-amplitude. The obtained S-N curve and stress-displacement 
responses allowed for identification of three distinct fatigue regimes as follows:

- High cycle fatigue R-phase regime at moderate displacements. A life-time larger than runout set at $1.5 \times 10^{6}$ cycles.

- Low cycle fatigue R-phase regime at larger displacements featuring amplitude dependent life time ranging from $10^{5}$ to $10^{4}$ cycles

- Low cycle fatigue MT regime with life-times in the range of $10^{3}$ cycles

The activity of the austenite-R-phase transformation was confirmed by fatigue tests at a constant stressamplitude and different temperatures. Fatigue life-time exceeding runout was confirmed for higher temperature tests $\left(80^{\circ} \mathrm{C}\right.$ and $\left.150^{\circ} \mathrm{C}\right)$ where the R-phase transformation did not occur whereas the wire broke at much lower number of cycles till failure at lower temperature where the R-phase transformation did occur.

Finally, a "Fatigue failure advanced warning" in terms of pronounced hysteresis appearing on stressdisplacement curve in final 100 cycles before the failure is proposed.

\section{References}

1. S. Subresh, Fatigue of Materials. 2004.

2. S. Eucken and T. Duerig, "The effects of pseudoelastic prestraining on the tensile behaviour and two-way shape memory effect in aged NiTi," Acta Metall., vol. 37, no. 8, pp. 2245-2252, 1989.

3. P. Sedmák, P. Šittner, J. Pilch, and C. Curfs, "Instability of cyclic superelastic deformation of NiTi investigated by synchrotron X-ray diffraction," Acta Mater., vol. 94, pp. 257-270, 2015.

4. K. . Melton and O. Mercier, "Fatigue of NITI thermoelastic martensites," Acta Metall., vol. 27, no. 1, pp. 137-144, 1979.

5. P. Šittner, M. Landa, P. Lukáš, and V. Novák, "Rphase transformation phenomena in thermomechanically loaded NiTi polycrystals," Mech. Mater., vol. 38, no. 5-6, pp. 475-492, 2006.

6. S. Miyazaki, K. Mizukoshi, T. Ueki, T. Sakuma, and Y. Liu, "Fatigue life of $\mathrm{Ti}-50$ at.\% Ni and $\mathrm{Ti}-$ $40 \mathrm{Ni}-10 \mathrm{Cu}$ (at.\%) shape memory alloy wires," Mater. Sci. Eng. A, vol. 273-275, pp. 658-663, Dec. 1999.

7. M. F.-X. Wagner and G. Eggeler, "Stress and strain states in a pseudoelastic wire subjected to bending rotation," Mech. Mater., vol. 38, no. 11, pp. 1012-1025, Nov. 2006.

8. A. R. Pelton, J. Fino-Decker, L. Vien, C. Bonsignore, P. Saffari, M. Launey, and M. R. Mitchell, "Rotary-bending fatigue characteristics of medical-grade Nitinol wire.," J. Mech. Behav. Biomed. Mater., vol. 27, pp. 19-32, Nov. 2013.

9. M. Frotscher, P. Nörtershäuser, C. Somsen, K. Neuking, R. Böckmann, and G. Eggeler,
"Microstructure and structural fatigue of ultra-fine grained NiTi-stents," Mater. Sci. Eng. A, vol. 503, no. 1-2, pp. 96-98, Mar. 2009.

10. M. Frotscher, K. Neuking, R. Böckmann, K.-D. Wolff, and G. Eggeler, "In situ scanning electron microscopic study of structural fatigue of struts, the characteristic elementary building units of medical stents," Mater. Sci. Eng. A, vol. 481-482, pp. 160-165, May 2008.

11. S. W. Robertson, Stankiewicz, Gong, and R. O. Ritchie, "Cyclic Fatigue of Nitinol," Proc. Int. Conf. Shape Mem. Superelastic Technol. SMST2003, 2006.

12. C. Maletta, E. Sgambitterra, F. Furgiuele, R. Casati, and a. Tuissi, "Fatigue properties of a pseudoelastic NiTi alloy: Strain ratcheting and hysteresis under cyclic tensile loading," Int. J. Fatigue, vol. 66, pp. 78-85, 2014.

13. C. M. Otsuka, K; Wayman, Shape Memory Materials. Cambridge: Cambridge University Press, 1998.

14. G. Eggeler, E. Hornbogen, a Yawny, a Heckmann, and M. Wagner, "Structural and functional fatigue of NiTi shape memory alloys," Mater. Sci. Eng. A, vol. 378, no. 1-2, pp. 24-33, Jul. 2004.

15. W. Dixon and A. Mood, "A method for obtaining and analyzing sensitivity data," J. Am. Stat. ..., vol. 43, no. 241, pp. 109-126, 1948. 